\section{Estudo \\ Ecidebate}

em CAStão

Planejamento
Revista Estudo \& Debate, Lajeado, v. 28, n. 4, 2021. ISSN 1983-036X

DOI: http://dx.doi.org/10.22410/issn.1983-036X.v28i4a2021.2878

\title{
ANÁLISE DAS POLÍTICAS DE GESTÁO EM INSTITUIÇÓES COMUNITÁRIAS DE ENSINO SUPERIOR DO RIO GRANDE DO SUL
}

\author{
Julian Israel Limaํㅗ Jaime Laufer ${ }^{2}$
}

\begin{abstract}
Resumo: Este estudo tem como objetivo analisar as políticas de gestáo em Instituiçóes Comunitárias de Ensino Superior participantes do COMUNG frente ao cenário da educação superior no Rio Grande do Sul. A metodologia é de natureza qualitativa com delineamento descritivo e exploratório. Foram realizadas entrevistas com os gestores de nove ICES, utilizando um roteiro de entrevista semiestruturado. Como principais resultados, verificou-se que o conjunto pesquisado é composto por Instituiçôes de alta complexidade de gestáo, o que resulta das particularidades desse tipo de organizaçáo. Aspectos como a democracia, a multiplicidade de áreas do conhecimento e os elementos decorrentes dessas particularidades, sobretudo o aspecto político, contribuem para o estabelecimento de uma estrutura altamente desafiante para seus gestores. As políticas de gestáo institucional do grupo avaliado permitem, em alguns casos, a preponderância de aspectos políticos em detrimento de aspectos técnicos financeiros nas tomadas de decisóes, assumindo as ICES, muitas vezes, perdas financeiras para a obtenção de resultados não financeiros. Entretanto, os entrevistados demonstram que essa é uma característica inerente ao caráter comunitário, democrático e de priorização da qualidade acadêmica, o que se confirma pelos bons resultados nas avaliaçóes do Ministério da Educação apresentados pelas ICES em questão.
\end{abstract}

Palavras-chave: Políticas de gestão; Instituiçóes Comunitárias de Ensino Superior; Gestão universitária.

\section{ANALYSIS OF MANAGEMENT POLICIES IN COMMUNITY HIGHER EDUCATION INSTITUTIONS IN RIO GRANDE DO SUL}

\begin{abstract}
This study aims to analyze the management policies in Community Higher Education Institutions participating in COMUNG in view of the higher education scenario in Rio Grande do Sul. The methodology is of a qualitative nature with a descriptive and exploratory design. Interviews were conducted with the managers of nine ICES, using a semi-structured interview script. As main results, it was verified that the researched set is composed of Institutions of high management complexity, which results from the peculiarities of this type of organization. Aspects such as democracy, the multiplicity of areas of knowledge and the elements resulting from these particularities, especially the political aspect, contribute to the establishment of a highly challenging structure for its managers. The institutional management policies of the evaluated group allow, in some cases,
\end{abstract}

1 Mestre em Administração pelo PPGA da UNISC; Docente no Departamento de Gestâo de Negócios e Comunicação na UNISC.

2 Mestre em Engenharia de Produção pela UFSM; Docente permanente no Mestrado Profissional em Administraçáo e no Departamento de Gestão de Negócios e Comunicação na UNISC. 
the preponderance of political aspects to the detriment of technical financial aspects in decision making, with the ICES often assuming financial losses to obtain non-financial results. However, the interviewees demonstrate that this is an inherent characteristic of the community, democratic and prioritizing academic quality, which is confirmed by the good results in the assessments of the Ministry of Education presented by the ICES in question.

Keywords: Management policies; Communitarian Institutions of Higher Education; University management.

\section{INTRODUÇÁO}

O ensino superior passa por constantes adaptaçóes e desafios ao longo dos últimos anos no Brasil. Complementar a isso, Balzer, Brodke e Kizhakethalackal (2015) dissertam que o aumento da competitividade devido ao declínio no número de alunos com acesso à universidade, aliado a concorrência, desafiam diariamente as instituiçôes de ensino para manterem-se viáveis, tendo em vista a carência de incentivos por parte do Governo $\mathrm{e}$, também, às limitaçóes financeiras dos estudantes, os quais não encontram oferta de financiamentos e bolsas em volume adequado.

Em relação às Políticas e Gestáo da Educação Superior no Brasil, o Conselho Nacional de Educação (2020) reafirma que a ampliação com qualidade da educação superior no País é uma necessidade e para a efetivação, existe uma demanda de políticas para o incremento substantivo de políticas de expansão por meio da consolidação e garantia de padróes de qualidade, política de avaliação e regulação para todo o sistema. No mesmo sentido, Díez et al. (2020) destacam que nas últimas duas décadas o planejamento de curto prazo tem aumentado neste tipo de organização por consistir em planos de fixação de metas com o objetivo de melhorar os padróes previamente estabelecidos.

Entretanto, enquanto não ocorrem açóes efetivas, as Instituiçóes de Ensino Superior - IES precisam desenvolver novos mecanismos que permitam aumentar sua eficiência, sem perder qualidade de ensino, atraindo e mantendo o número necessário de alunos para viabilizar suas atividades educacionais. Além disso, embora o PNE - Plano Nacional de Educação preveja o aumento do número de jovens matriculados no ensino superior até 2024, com a intenção de atingir a taxa líquida de matrículas de 33\% da população de 18 a 24 anos (BRASIL, 2014), o que se observa no contexto educacional atualmente é um movimento em sentido contrário.

Diante da profunda mudança no cenário político-econômico brasileiro, cujos maiores efeitos começaram a ser sentidos a partir de 2015, teve reflexo direto em todos os ramos da economia, desacelerando diversos setores e gerando indicadores negativos para muitas organizaçōes (WENDLAND et al., 2021) e com a educação superior não foi diferente. Em meio a esse cenário, as Instituiçóes Comunitárias de Ensino Superior - ICES têm empreendido esforços para manterem seu equilíbrio financeiro e sobreporem os obstáculos da diminuição da oferta de financiamento pelos Governos aos estudantes e pela redução do número de disciplinas matriculadas por aluno em função da diminuição de sua capacidade de pagamento.

Reconhecidas pelos órgãos governamentais, as ICES representam um tipo peculiar de Instituição de Ensino Superior. Com a publicação da Lei 12.881 em 2013, as instituiçóes comunitárias passaram a ser definidas como um tipo específico de Instituição de Ensino 
Superior, entre o público e o privado, caracterizando-se como organizações públicas não estatais, sem fins lucrativos e mantidas por associaçóes ou fundações (BRASIL, 2013). No Rio Grande do Sul, as ICES estão congregadas através do Consórcio das Universidades Comunitárias Gaúchas - COMUNG, composto por quinze instituiçóes, o que representa o maior sistema de educaçáo superior no Estado (COMUNG, 2020). As dificuldades resultantes do cenário político-econômico atual têm atingido a todas essas instituiçóes e o entendimento da forma como as mesmas têm enfrentado essas situações é de grande relevância.

As ICES participantes do COMUNG atendem a mais de 180.000 universitários gaúchos, oferecendo mais de 1.400 cursos de graduação e pós-graduação (COMUNG, 2020) e cada instituição tem a característica de profundo envolvimento e influência nas comunidades adotadas. Todavia, este tipo de organização enfrenta diversos desafios integrando, entre tantas demandas de gestáo, o planejamento a curto e longo prazo, bem como a busca por soluçôes efetivas para manutenção da competitividade. Diante de um ambiente interno pluralístico e democrático, torna-se fundamental compreender as políticas de gestão vivenciadas em instituiçôes de ensino superior. Posto isso, este estudo objetivou analisar as políticas de gestão em Instituiçóes Comunitárias de Ensino Superior participantes do COMUNG frente ao cenário da educação superior no Rio Grande do Sul.

\section{FUNDAMENTAÇÃO TEÓRICA}

\subsection{O mercado educacional brasileiro}

Durante muito tempo, o acesso ao ensino superior no Brasil foi restrito aos residentes nos grandes centros urbanos e àquelas pessoas cujas condiçôes financeiras permitissem seu deslocamento do interior às capitais. A partir da década de 1950, uma transformação passou a ocorrer na educação superior brasileira, culminando na reforma universitária de 1968, período no qual a abrangência dessa categoria de ensino ainda era considerada limitada no País (MACHADO; BARASSUOL, 2019).

A Constituição de 1988 atribuiu as obrigaçóes, no que diz respeito à educação, aos Municípios, Estados e ao Distrito Federal. A partir desse marco legal, as responsabilidades sobre a educaçấo infantil, o ensino fundamental e o ensino médio foram claramente definidas e distribuídas entre os Municípios, o Distrito Federal e os Estados. Entretanto, no que tange à educação superior, a Constituição não atribui a responsabilidade a nenhum dos entes públicos (ROTH et al., 2013; GÓIS; SALERNO, 2021).

Machado e Barassuol (2019) atribuem essa falta de clareza em relação à condiçáa de responsabilidade sobre a educação superior no Brasil a razão do surgimento de diversas Instituiçôes de Ensino Superior, as quais são, em sua maioria, não estatais. De acordo com o Censo da Educação Superior (INEP, 2019), verifica-se que 75,8 \% das instituiçóes de ensino superior são privadas e, 24,2\%, são públicas.

Quanto aos ingressantes por rede e modalidade de ensino, a rede pública de ensino superior na modalidade presencial predomina com 94,2\%, enquanto, na rede privada ingressam cerca de 49,3\% na mesma modalidade (INEP, 2019). Portanto, na rede privada 
a maioria $(50,7 \%)$ dos ingressantes predominam na modalidade EaD. Conforme o INEP (2019), em 2018, a modalidade de Educação a Distância ultrapassou dois milhóes de alunos, e, em 2019, tinha 28,4\% dos alunos de graduaçáo no país, evidenciando que desde 2015, o número de matrículas na modalidade presencial vem diminuindo.

Sarquis et al. (2017) afirmam que as instituiçóes comunitárias de ensino superior precisam manter contatos frequentes com os estudantes e um relacionamento de médiolongo prazo pois, existe uma predominância em quantidade de matriculas ofertadas neste tipo de instituições. Ainda, segundo Campos et al. (2017), além destas instituições atuarem na produção e compartilhamento de conhecimentos por meio da pesquisa e atuarem na formação de estudantes, também dedicam esforços para a socialização do conhecimento com a comunidade.

De acordo com o INEP (2019), o número de ingressos em cursos de graduação a distância tem aumentado substancialmente nos últimos anos, uma vez que, o total de ingressantes foi de 16,1\% em 2009 para 43,8\% em 2019. Ainda, verifica-se que o número de ingressos nos cursos de graduação presenciais, nos últimos cinco anos diminuiu 14,3\%. Ademais, na rede pública, quase $20 \%$ das vagas de graduação não são preenchidas. A partir de análises de mercado, observa-se que um público expressivo tem postergado a decisão de entrar em um curso superior. Por outro lado, esse público que atualmente está postergando seu ingresso na graduação tende a ingressar tão logo a situação econômica melhore.

\subsection{As Instituiçóes Comunitárias de Ensino Superior}

No ano de 2013 entrou em vigor a Lei No 12.881, que dispóe sobre a definição, qualificação, prerrogativas e finalidades das Instituiçóes Comunitárias de Ensino Superior. Trata-se do marco legal das ICES, há muito tempo aguardado e conquistado a partir de uma mobilização nacional por parte de seus dirigentes e órgãos de representação. Com essa condição, as ICES representam um terceiro modelo de Instituição de Ensino Superior, o qual é distinto das públicas e privadas.

A referida legislação qualifica como comunitárias as instituições que, cumulativamente, tiverem as seguintes características:

I - estão constituídas na forma de associação ou fundação, com personalidade jurídica de direito privado, inclusive as instituídas pelo poder público; II - patrimônio pertencente a entidades da sociedade civil e/ou poder público; III - sem fins lucrativos, assim entendidas as que observam, cumulativamente, os seguintes requisitos: a) não distribuem qualquer parcela de seu patrimônio ou de suas rendas, a qualquer título; b) aplicam integralmente no País os seus recursos na manutenção dos seus objetivos institucionais; c) mantêm escrituração de suas receitas e despesas em livros revestidos de formalidades capazes de assegurar sua exatidão; IV - transparência administrativa, nos termos dos artigos $3^{\circ}$ e $4^{\circ}$; $\mathrm{V}$ - destinação do patrimônio, em caso de extinção, a uma instituição pública ou congênere (BRASIL, 2013).

Entre as vantagens do enquadramento na condição de comunitárias, destaca-se a possibilidade que as Instituiçôes passaram a ter de concorrer em editais de órgãos públicos, anteriormente destinados apenas às IES públicas. Essa habilitação também permite que as 
comunitárias recebam recursos orçamentários do governo. A legislação ainda prevê que as ICES sejam consideradas alternativas na oferta de serviços públicos estatais nos casos em que os mesmos não sejam proporcionados de forma direta pelos órgãos estatais (BRASIL, 2013).

Para além disso, as ICES possuem a sustentabilidade, a efetividade social e complementaridade das atividades/funçôes como princípios de gestão e como não são mantidas pelo poder público, necessitam obter recursos pelas matriculas/mensalidades de estudantes para zelar pela segurança econômico-financeira da instituição (ZANIN et al., 2015). Outrossim, as ICES procuram executar atividades que atendam às necessidades da sociedade que não são supridas pelo setor público, principalmente, a demanda por serviços educacionais (HANSMANN, 1980; HOFMANN; MCSWAIN, 2013; ZAINON; ATAN; WAH, 2014; THIEMANN et al., 2018).

Tendo em vista a garantia de práticas que promovam a transparência e a participação dos órgãos e das representaçóes que compóem a comunidade constituinte das ICES, para pleitear a qualificação como tal, também é necessário que o estatuto da entidade requerente apresente um conjunto de normas que disponham sobre:

I - a adoção de práticas de gestão administrativa, necessárias e suficientes para coibir a obtenção, de forma individual ou coletiva, de privilégios, benefícios ou vantagens pessoais; II - a constituição de conselho fiscal ou órgão equivalente, dotado de competência para opinar sobre os relatórios de desempenho financeiro e contábil e sobre as operaçóes patrimoniais realizadas, emitindo pareceres para os organismos superiores da entidade; III - normas de prestação de contas a serem atendidas pela entidade, que determinarão, no mínimo: a) a observância dos princípios fundamentais de contabilidade e das Normas Brasileiras de Contabilidade; b) publicidade, por qualquer meio eficaz, no encerramento do exercício fiscal, do relatório de atividades e das demonstraçôes financeiras da entidade; c) prestação de contas de todos os recursos e bens de origem pública; IV - participação de representantes dos docentes, estudantes e técnicos administrativos em órgãos colegiados acadêmicos deliberativos da instituição (BRASIL, 2013).

Com o objetivo de integrar e fortalecer individualmente as ICES situadas no Estado do Rio Grande do Sul, em 1996 foi constituído o COMUNG - Consórcio das Universidades Comunitárias Gaúchas. Entre as conquistas alcançadas, destaca-se a troca de experiências, a qualificação dos diversos agentes envolvidos em seus processos de ensino, pesquisa e extensão e a realização de fóruns e eventos integrativos entre as diversas áreas técnicas para a troca de conhecimentos e capacitação.

Além disso, a mobilização e busca conjunta por convênios e políticas públicas, incentivos e subsídios à formação acadêmica das comunidades onde as ICES estão inseridas também representam exemplos de ações que continuamente são tomadas pela entidade. A promoção do desenvolvimento tecnológico, de açóes de inovação, empreendedorismo e atividades culturais também são fortes marcas do conjunto de açóes propostos pelo Consórcio das Universidades Comunitárias Gaúchas (COMUNG, 2020).

O COMUNG é o maior sistema de educação superior em atuação no Estado do Rio Grande do Sul, representando uma rede de educação, ciência e tecnologia. Além do COMUNG, as ICES também contam com um órgão representativo a nível nacional, 
a ABRUC - Associação Brasileira de Universidades Comunitárias. Formada por 66 Instituições, a ABRUC foi constituída em 1995 e congrega aquelas que apresentarem conceitos de 3 a 5 no IGC - Índice Geral de Cursos, do SINAES. Atuando em conjunto com os demais órgãos de representação das ICES, como é o caso do COMUNG, a ABRUC articula em Brasília os interesses das diversas comunidades atingidas pelas Instituiçóes que as atendem (ABRUC, 2020).

\subsection{Políticas de gestáo}

Nas últimas duas décadas as pesquisas acerca das políticas de gestão em Instituiçôes de Ensino Superior destacam que o planejamento de curto prazo tem aumentado pois, o planejamento neste tipo de instituição consiste em planos de fixação de metas com o objetivo de melhorar os padróes previamente estabelecidos (DÍEZ et al., 2020). Portanto, o planejamento visa contribuir para o estabelecimento de estruturas organizacionais, particularmente na melhoria dos resultados de aprendizagem dos alunos e, ao mesmo tempo, fomentando a capacidade das Instituiçóes de Ensino para gerenciar a mudança (HOQUE et al., 2011; STOLL, 2009; DÍEZ et al., 2020).

Todavia, os relacionamentos e as comunicaçóes são características essenciais se a melhoria da qualidade deve ser implementada nas escolas (JEFFERSON; ANDERSON, 2017). No mesmo sentido, os gestores orientam o planejamento abrangente, delegam tarefas a equipes diferentes e são flexíveis na melhoria das relações entre docentes e alunos (BELL, 2018; STEIN, 2016), além de buscar compreender as necessidades sociais, melhorando a qualidade do ensino constantemente.

A nível organizacional, as IES criam e mantêm as condiçóes necessárias, considerando as políticas, culturas e estruturas que facilitam a aprendizagem e as experiências orientadas para as competências e os gestores garantem os inter-relacionamentos e a sinergia dos processos, tomada de decisão e comprometimento de gestão (STOLL, 2009). Ainda, garantir condiçóes organizacionais que fortaleçam a capacidade escolar de mudança é um pré-requisito para unificar o desenvolvimento profissional dos educadores com o desenvolvimento escolar (THOONEN et al., 2012; DÍEZ et al., 2020).

\section{METODOLOGIA}

O estudo é de natureza qualitativa com delineamento descritivo e exploratório, tendo como universo de pesquisa todas as instituiçóes de ensino superior participantes do COMUNG. A amostra foi selecionada por conveniência e as instituiçôes foram convidadas a participar do estudo, obtendo-se um total de 9 ICES. Como estratégia de pesquisa optouse por um estudo de caso com o objetivo de lançar um olhar detalhado sobre as políticas de gestão em Instituições Comunitárias de Ensino Superior participantes do COMUNG frente ao cenário da educação superior no Rio Grande do Sul. Segundo Yin (2015), o estudo de caso é uma forma de investigação empírica em profundidade, que permite a observação de um fenômeno em seu contexto social.

Os dados foram coletados a partir de entrevistas com os Pró-Reitores Administrativos de nove ICES, utilizando um roteiro de entrevista semiestruturado. Uma das fontes mais 
importantes de dados para os estudos de caso são as entrevistas, pois, elas se caracterizam por serem semelhantes a conversas guiadas e não investigaçóes totalmente estruturadas. Mesmo que uma linha consistente de investigaçáo seja observada, no estudo de caso a corrente de questōes deve ser, de certa forma, fluída e não rígida (YIN, 2015). Além disso, a entrevista semiestruturada é caracterizada pela liberdade que o pesquisador possui para exercitar sua iniciativa no acompanhamento da resposta a cada pergunta (HAIR et al., 2005).

As entrevistas foram gravadas e posteriormente transcritas, para viabilizar a realização da análise dos resultados. Conforme Yin (2015), o registro em áudio permite uma interpretação mais precisa das entrevistas em comparação com a simples realização de anotaçóes no decorrer das mesmas. Entretanto, conforme orienta o autor, foi solicitada a permissão dos entrevistados antes de iniciar as gravaçóes, obtendo-se total aceitação para utilização da ferramenta, mediante a instruçáo de que as perguntas que não estivessem de acordo, poderiam não ser respondidas.

A análise das entrevistas foi realizada com o emprego da técnica de análise de conteúdo de Bardin (2015). A sistematização dos resultados foi realizada a partir da classificação das entrevistas em unidades de informaçáo, as quais foram estruturadas em categorias de acordo com os elementos norteadores, pré-estabelecidos pelos autores com base no roteiro semiestruturado, apresentados no Quadro 1.

Quadro 1 - Descrição das categorias e elementos norteadores.

\begin{tabular}{|c|c|}
\hline Categorias & Elementos norteadores das categorias \\
\hline Dificuldades & $\begin{array}{l}\text { Perdas financeiras; } \\
\text { Tomada de decisôes; } \\
\text { Associação do conceito de universidade comunitária ao assistencialismo; } \\
\text { Açốes de redução de custos; } \\
\text { Potencial de reestruturação da pesquisa; } \\
\text { Aplicação dos conceitos de gestão; } \\
\text { Percepção sobre o Superávit. }\end{array}$ \\
\hline Boas práticas & $\begin{array}{l}\text { Planejamento com a utilização da lógica do BSC; } \\
\text { Aceitação de proposiçóes de melhorias; } \\
\text { Busca constante de novos serviços; } \\
\text { Elevado grau de controle da gestão; } \\
\text { Foco em qualificação para obter vantagem competitiva; } \\
\text { Profissionalização da gestão. }\end{array}$ \\
\hline $\begin{array}{c}\text { Preocupaçóes dos } \\
\text { gestores }\end{array}$ & $\begin{array}{l}\text { Comprometimento financeiro de curto e longo prazo; } \\
\text { Imprevisibilidade do mercado; } \\
\text { Liquidez e manutençáo do fluxo de caixa; } \\
\text { Repasses de recursos governamentais. }\end{array}$ \\
\hline $\begin{array}{l}\text { Decorrências do } \\
\text { modelo democrático }\end{array}$ & $\begin{array}{l}\text { Aspectos políticos internos; } \\
\text { Diversidade de qualificação profissional; } \\
\text { Autogestão; } \\
\text { Aspecto democrático e político versus gestão; } \\
\text { Estrutura organizacional. }\end{array}$ \\
\hline
\end{tabular}

Fonte: Autores (2020) 
Para manter o anonimato dos entrevistados, nomes fictícios foram atribuídos às instituiçóes, sendo cada uma vinculada, de forma aleatória, a uma das nove primeiras letras do alfabeto, partindo da letra "A" até a letra "I". Assim, conforme as informaçóes ou trechos das entrevistas são apresentados, apenas a letra atribuída foi mencionada como referência.

\section{ANÁLISE DOS RESULTADOS}

Foram entrevistados nove Pró-reitores Administrativos, representantes das Instituiçóes pesquisadas e responsáveis na atuação da gestão, representando a participação de $60 \%$ das entidades que compóem o COMUNG. Em relação ao perfil dos entrevistados e das Instituiçóes participantes, o Quadro 2 apresenta uma breve descrição do perfil dos respondentes da pesquisa.

Quadro 2 - Perfil dos entrevistados

\begin{tabular}{|c|c|c|}
\hline \multicolumn{3}{|c|}{ Tempo de atuaçáo no cargo } \\
\hline Tempo de atuaçáo (anos) & Núm. & $\%$. \\
\hline Até 3 & 5 & $56 \%$ \\
\hline De 4 a 6 & 1 & $11 \%$ \\
\hline De 7 a 9 & 2 & $22 \%$ \\
\hline De 10 a 12 & 1 & $11 \%$ \\
\hline Total & 9 & $100 \%$ \\
\hline
\end{tabular}

Fonte: Autores (2020)

É possível observar que mais de 50\% têm até três anos de atuação no cargo atual, o que pode estar associado ao fato de que muitos dos cargos da gestáo superior nas ICES são eletivos e apresentam prazo máximo de ocupação. Observa-se, ainda, que um terço dos entrevistados ocupa o cargo por tempo superior a sete anos. Além do exposto, quando questionados sobre a existência de experiência pregressa na mesma função em outra organização, 67\% informaram que já realizaram a mesma atividade anteriormente, o que corresponde a dois terços dos entrevistados.

\subsection{Políticas de gestáo institucional}

A forma como as decisões são tomadas em uma organização, bem como a maneira como os processos são organizados e executados, assim como as políticas e práticas adotadas nas operações acabam por refletir na gestão como um todo. Para facilitar o entendimento, as abordagens dos respondentes foram dispostas em categorias e subcategorias possibilitando quantificar em percentuais de cada ação.

A categoria das dificuldades apresenta a concentração das menções a respeito das principais dificuldades encontradas pelos gestores financeiros entrevistados na condução das finanças Institucionais e podem possibilitar um meio de se alcançar alternativas para que se possa contornar essas questóes. Para 56\% dos entrevistados, as suas Instituiçóes assumem perdas de ordem financeira para obterem resultados não financeiros com muita frequência. 
Essa questão geralmente está associada, conforme os respondentes, a aspectos da pesquisa e da extensão, sobretudo em atividades que envolvam contrapartida do poder público.

Para os pesquisados, as atividades são importantes para as ICES em função de seus objetivos sociais, mas acabam por gerar prejuízos ou dificuldades para a cobertura de custos em nome desse princípio. Esse elemento é traduzido na fala de um dos gestores, quando aborda a questão de projetos com municípios:

\begin{abstract}
Cada projeto com a área pública, zero a zero, é maravilhoso. Mas sempre vem uma despesa junto. E esses aspectos impactam, mas não é um impacto significativo diante do tamanho do nosso orçamento, ainda, né. É suportável, mas preocupa se começa a crescer, entendeu? Tem que ter controle. E a gente faz a crítica 'olha aqui ó, o Prefeito não pagou, já estamos há seis meses'. (E).
\end{abstract}

Quanto às ações de redução de custos, notou-se que duas ICES, o que corresponde a 22\% das participantes da pesquisa, manifestaram a existência de dificuldades na aplicação de ações de redução de custos. Da mesma forma, as mesmas duas ICES manifestaram que existe uma questão associada à cultura Institucional que dificulta a execução desse tipo de ação.

Para o gestor da Universidade A, “[...] há uma lentidão entre a execução do plano acadêmico. Nós projetamos a descontinuidade de um curso, mas não se consegue executar a redução do custo na velocidade que a gente projeta.”. A visão é complementada pela fala de outro gestor financeiro, que aborda a dificuldade enfrentada no trecho a seguir:

[...] quando a gente entra em crise a gente começa a pensar mais fortemente em custo, em redução de custo. Isto é perigoso, né, porque nós deveríamos ter uma cultura um pouco mais, vou chamar de séria, talvez não seja a palavra certa, tá, uma cultura mais adequada para a questão do cuidado com o custo, ou seja, nos momentos bons, a gente tem que pensar em adequar custos. $\mathrm{O}$ fato é que em momentos bons a gente aumenta custo. A gente aumenta numa proporção não muito ideal, que não acompanha exatamente a variável receita, crédito matriculado, e aumenta muito custo fixo, tá, então quando eu aumento custo fixo num momento de crescimento, se a curva inverte, tem uma obviedade aí de diminuir custo fixo. (D).

Outra questão mencionada por $22 \%$ dos respondentes trata da dificuldade dos gestores das demais áreas Institucionais em tomar decisóes, o que se complementa com a ocorrência de outros $22 \%$ que abordaram o fato de que os diversos gestores Institucionais carecem de conhecimentos financeiros básicos para qualificar suas decisóes.

Em seu discurso, os entrevistados mencionam que o mérito das questóes em análise, muitas vezes, acaba se sobrepondo em relação à questão técnica financeira. Para eles, gestores acadêmicos com mais conhecimento sobre o econômico e o financeiro terão decisões mais conscientes e de acordo com os objetivos relacionados à sustentabilidade Institucional.

Dificuldade semelhante também é abordada por $22 \%$ dos participantes, os quais afirmam que o superávit é visto como algo negativo em suas Instituições, por estar culturalmente associado ao lucro. Essa questão, segundo os respondentes, dificulta a atuação Institucional no sentido de trabalhar para reduçáo das dívidas e aumento dos investimentos 
com recursos próprios, o que fica demonstrado na transcrição da fala de um dos Pró-reitores administrativos, conforme segue:

Eu não estou dizendo que é certo ou errado, eu estou dizendo que o meu posicionamento acha que isso leva para frente um problema, ali, que nós não temos a cultura de trabalhar para o superávit. $\mathrm{O}$ trabalhar para o superávit, não quer dizer que alguém vai ter lucro, só quer dizer que a gente aumenta a nossa capacidade de melhorar o serviço em funçáo da nossa capacidade de investimento. Mas essa é a nossa cultura. (D)

Para um dos entrevistados, dentre os aspectos que dificultam a gestão institucional, destaca-se a equivocada associação do conceito de universidade comunitária ao assistencialismo fazendo com que a comunidade e membros da própria organização entendam que deve haver gratuidade de açóes em que a mesma não é prevista. Em seu relato, o gestor da Universidade E descreve esse aspecto e o que ele representa.

\begin{abstract}
Imagina esse caráter comunitário em uma estrutura colegiada aberta como a nossa. São muitos gestores e essas pessoas têm dificuldade de entender o que é comunitário. Comunitário não é ser assistencialista. Então há uma corrente dentro da Instituição que acha que tem que ser assistencialista. E aí entra a nossa visão administrativa de que nós temos uma estrutura instalada, ela está a serviço da comunidade, mas ela tem que ser remunerada. O que está se beneficiando, ele já tem o benefício de dispor dessa estrutura instalada com capacidade técnica para atender a demanda, ele não vai ter que investir numa estrutura como essa, mas ele tem que pagar os custos, pelo menos isso, dessa estrutura. E essa dificuldade da área acadêmica de compreender que a Instituiçáo presta um serviço comunitário, ela contribui para o desenvolvimento da regiáo, com recurso de mensalidade de aluno e ela deve prestar esse serviço, mas ela tem que ser remunerada, não pode ser gratuito. Então existe esse grupo de professores principalmente e gestores/professores que pensam assim, existe uma comunidade que também pensa assim 'não, é comunitária, eu vou lá e eles vão fazer para mim'. Isso em todos os setores. (E).
\end{abstract}

A visão de que aquilo que se ensina nas universidades, em termos de gestão, não é aplicado em sua totalidade foi abordada por um dos gestores, o qual descreve o ambiente interno com dificuldades de aplicação de boas práticas de gestão junto aos gestores das diversas áreas institucionais, pelo fato de que muitas dessas açóes representam a perda de poder de atuaçáo pelos mesmos.

Como toda a boa universidade, nós não usamos todas as ferramentas que nós ensinamos, né.
Isso é padrão. Mas, sim, tem possibilidades de outras ferramentas que poderia se trazer [...].
Mas seria preciso vencer as resistências internas. Porque, quando você tira a possibilidade
de as pessoas arbitrarem o uso dos recursos. Não, isso é uma decisão meritocrática ou isso
é uma decisão baseada só em indicadores? Enfim, você está retirando o poder das pessoas
de fazer aquele agrado para alguém que pudesse estar fazendo e, claro, que isso é sempre
difícil de implementar. (C).

Esse paradoxo também é evidenciado na pesquisa de Dittadi e Souza (2009), que estudou a adoção de práticas de controladoria em IES. O autor menciona ter identificado que, embora sejam produtoras e disseminadoras de conhecimento, as Instituições não utilizam todo esse conhecimento em proveito próprio. 
A necessidade de reorganização da pesquisa para que ela passe a gerar como resultados o conhecimento, a inovaçáo e receita foi mencionada por um dos gestores entrevistados como sendo uma das dificuldades a serem contornadas, tendo em vista os altos investimentos necessários nessa área, os quais pesam na estrutura de custos das universidades. Cabe destacar que o volume de investimentos necessários para se manter a pesquisa também foi mencionado por outros gestores, sobretudo nos itens em que se discutiu a representatividade da folha de pagamento em relação à receita líquida.

O gestor em questão apresenta uma explanação bastante completa, com sua visão a respeito do que seria o ideal em relação à pesquisa, qualificando a mesma como o principal objetivo da academia, cuja responsabilidade maior seria de gerar um ciclo envolvendo inovação, produto e receita, se retroalimentando sempre que possível. A seguir o trecho da entrevista que descreve o elemento mencionado:

[...] a pesquisa, ela tem ainda uma característica muito acadêmica, e isso não é propriamente uma crítica, nada contra a pesquisa, ela é essencialmente o principal afazer da academia. Mas ela não completa um ciclo, porque a pesquisa deveria gerar inovação, inovação deveria gerar produto, produto deveria gerar receita para financiar pesquisa. Então nós temos um fluxo aí que ele vai até a metade, né. Tem investimento de recurso em pesquisa, ela pode eventualmente gerar melhorias, mas o fluxo completo de voltar dinheiro para refinanciar a pesquisa, e aí reverter dinheiro para a Instituição, ela não acontece. Isso é uma série de fatores. Nós não temos um ambiente adequado com essa visão da inovação gerando recursos no meio econômico. Então até no meio acadêmico. Os professores nossos, formados às vezes em instituições públicas, eu não diria que na sua totalidade, talvez nem na sua maioria, mas existem ainda alguns grupos que o fato de pesquisar é pesquisar por pesquisar, para chegar à alguma conclusão ou para enriquecer o lattes, alguma coisa do tipo. Então ainda existe um pouco desse pensamento e os demais que pensam diferente têm uma dificuldade de encontrar um ambiente que a gente chama hoje de um ecossistema de inovação. (F).

Dentro da categoria que trata das boas práticas, foram reunidos os elementos associados aos aspectos positivos verificados na aplicação das ações de gestão de curto prazo nas ICES pesquisadas. Diferente das demais categorias, esta apresenta a particularidade de ter baixo volume de ocorrências em cada uma das subcategorias, em função de se tratar de aspectos mais pontuais e específicos de cada instituição. Por esse motivo, a descrição dos itens que a compóem apresenta menor ocorrência de transcriçóes de trechos das entrevistas, com a finalidade de garantir o anonimato dos respondentes, considerando a especificidade dos temas tratados.

Para 44\% das ICES pesquisadas, a maioria das proposiçóes apresentadas pela PróReitoria Administrativa são aceitas nas diversas instâncias Institucionais. Esse aspecto traduz um conjunto de conceitos internos associados, conforme os próprios gestores, ao grau de preparo dos diversos agentes internos em relação à importância dos aspectos econômicos e financeiros, bem como dos relacionados à gestão propriamente dita.

Nessas ICES, os respondentes deixaram claro que existe uma consciência de que o papel da Pró-Reitoria Administrativa é dar parecer sobre a viabilidade econômica e financeira das açóes e decisóes que as demais áreas necessitam tomar, o que culturalmente é respeitado, inclusive, pelos reitores ou reitoras quando estes não têm perfil de formação na área a gestão. 
O elevado grau de controle exercido pela Pró-Reitoria Administrativa sobre o fluxo de gastos Institucionais impede que gastos não previstos sejam realizados em $44 \%$ das ICES participantes da pesquisa. Essas ações são apresentadas pelos respondentes como aspectos relacionados à sua forma de trabalhar e monitorar as questóes financeiras que, sempre que necessário, são discutidas e reavaliadas, mediante as devidas justificativas. As demais ICES mencionaram a ocorrência eventual de gastos não previstos, sendo que, uma delas, tem como prática não honrar pagamentos não autorizados, realizando a cobrança do próprio executor da compra.

As particularidades resultantes da estrutura colegiada, mencionadas pelos gestores como geradoras de certa morosidade em muitos momentos, são contornadas por um dos gestores através da realização de intensas negociaçôes com os diversos componentes internos dos órgãos colegiados e dos responsáveis pela execução de gastos institucionais.

Uma certa quantidade de energia é direcionada a essa atividade, conforme o entrevistado, mas há o entendimento de que isso faz parte do contexto da autogestáo e os resultados positivos são colhidos no decorrer do tempo. Uma das ações citadas pelo gestor em questão trata de uma revisão de orçamento realizada ao final do ano de 2014, a partir de uma análise de mercado realizada que apontava para uma inversão de curva de desempenho na economia.

Após intensas negociaçóes internas o orçamento foi revisto e o ano de 2015 foi iniciado com reduçôes, tendo sido essa a única Instituição entre as pesquisadas que conseguiu se antecipar à crise resultante da situação político-econômica que teve como um de seus elementos a restriçáo do FIES.

Em relação a esses fatos, o estudo de Stiebbe (2014) elenca a habilidade relacional e de negociação como a competência mais demandada pelos gestores universitários participantes de sua pesquisa, a qual destaca que esse tipo de atividade requer um conjunto de habilidades diferenciadas para que se possa dar conta das atividades que envolvem ensino, pesquisa e extensão com seus respectivos agentes.

Para contornar as dificuldades resultantes da diversidade de formaçóes dos profissionais ocupantes dos diversos cargos de gestâo existentes, uma das ICES adotou a prática de criar um programa interno de formação para os gestores, com vistas a profissionalizar a gestão Institucional.

Conforme o respondente, a rotatividade nos cargos e as diversas formaçóes de seus ocupantes levam à necessidade de fornecimento de conhecimentos técnicos da área da gestão, o que inclui os conhecimentos financeiros. Com isso, resultados positivos começaram a ser observados, na medida em que gestores que antes não dominavam aspectos financeiros passaram a entender melhor os processos e considerar tais elementos em suas decisóes, passando, também, a estarem mais interessados no andamento das metas estabelecidas.

A implantação de um planejamento estratégico com a vinculação do orçamento Institucional ao mesmo está sendo posta em prática por uma das ICES participantes da pesquisa, com vistas à aplicação das premissas do Balanced Scorecard (BSC). Conforme o gestor respondente, trata-se de um projeto cuja implantaçáo está sendo feita de forma 
gradativa, mas que tem objetivo de associar as açôes do planejamento financeiro e orçamentário às metas e indicadores do planejamento estratégico.

Para o gestor, os primeiros reflexos positivos já estão sendo observados, como a otimização do processo de planejamento orçamentário e a associação dos resultados econômicos e financeiros desejados a metas específicas da Instituição. Como forma de garantir o adequado suporte aos gestores de unidades acadêmicas, cujos ocupantes dos cargos têm prazo máximo de permanência nos mesmos, uma das ICES participantes da pesquisa estabeleceu a figura de um gestor administrativo em cada uma de suas unidades acadêmicas responsáveis pelas áreas do conhecimento dentro da Universidade.

$\mathrm{O}$ referido gestor administrativo de unidade se reporta ao gestor financeiro e administrativo institucional e tem a característica de perenidade no seu cargo. Conforme o respondente, essa medida possibilita que as demandas administrativas e financeiras sejam mais adequadamente avaliadas e tratadas, tendo em vista o perfil mais acadêmico dos gestores docentes.

A busca constante e sistemática por novos serviços resultantes da atividade acadêmica como fonte de receita foi citada por um dos respondentes da pesquisa como ação deliberadamente realizada para o atingimento de uma meta Institucional de redução da dependência das receitas provenientes de mensalidades dos alunos.

Para o gestor em questão, uma Universidade contém um conjunto muito grande de produtos que podem ser vendidos para gerar receita, partindo das atividades de ensino, pesquisa e extensão, ou ainda, pela exploração qualificada da estrutura instalada, como prédios, tecnologia, sistemas, entre outros.

Como forma de fazer frente à concorrência que atua com foco em preços baixos, duas ICES adotaram a estratégia de qualificar ainda mais seus cursos da área da saúde, os quais requerem uma estrutura que essa concorrência não possui, como forma de elevar seu número de alunos e, consequentemente, suas receitas.

Um dos gestores menciona que a evasão em cursos da área da saúde que passaram pela aplicação dessa política estão praticamente sem evasão. $\mathrm{O}$ outro gestor menciona que a ICES acabou se tornando uma referência em ensino na área da saúde na região onde está instalada, o que elevou a procura pelos estudantes.

A expansão do stricto sensu foi realizada por uma das ICES pesquisadas por meio da implementação de um programa de bolsas parciais com recursos Institucionais. Para o gestor entrevistado, antes a Universidade tinha um número muito menor de estudantes pagando mensalidades integrais e ocorria a ociosidade de vagas. Pela nova lógica implantada, a Instituição passou a ter mais estudantes pagando a metade dos valores, o que no valor global da receita representou um aumento que possibilitou, inclusive, a criação de novos Programas de stricto sensu.

A dificuldade de encaminhar cursos para a descontinuidade foi contornada por uma das ICES pesquisadas quando se estabeleceu e se formalizou institucionalmente um conjunto de critérios que, quando atingidos por três anos consecutivos por qualquer um dos cursos, o levam à descontinuidade. 
De acordo com o Pró-Reitor entrevistado, foi empreendido um grande esforço por parte da gestâo superior para estudar e validar esses critérios. Entretanto, depois que os mesmos estavam aprovados e formalizados internamente, passou a ser muito mais fácil e rápido realizar a descontinuidade de cursos considerados inviáveis, o que antes costumava ser demasiadamente moroso.

Como forma de evitar a redução de receitas em função do abandono dos estudos por parte dos estudantes, uma das Universidades pesquisadas criou um setor interno com a atribuição específica de trabalhar para evitar a evasão dos alunos. Com a realização de açóes ativas de relacionamento e acompanhamento dos acadêmicos, com direcionamento para crédito educativo, programas de bolsas ou renegociaçôes de dívidas, o gestor entrevistado afirma que foi possível garantir a manutenção de um número significativo de estudantes que estavam prestes a evadir, garantindo uma menor redução de receitas.

A categoria preocupaçóes dos gestores contém as respostas dos entrevistados em relação aos assuntos que mais lhes demandam preocupação e envolvimento no decorrer das suas atividades. Nesse sentido, $89 \%$ dos entrevistados afirma que a liquidez e a manutençáo do fluxo de caixa são as suas maiores preocupaçôes, que se traduz pela afirmaçáo do gestor financeiro da Universidade A, que afirma que "[...] procurar realizar o caixa, para que ele caiba dentro do nosso dia a dia, esse é o nosso grande foco.”.

Para o gestor da Universidade D, "o momento atual, ele requer uma preocupação grande com relação a fluxo de caixa", atribuindo essa dificuldade à questáo econômica atual e à reduçáo do número de alunos que vêm ocorrendo no ensino superior desde 2015. Os dados da pesquisa mostram que os gestores participantes da pesquisa estáo envolvendo grande parte dos seus esforços atualmente para garantir novas fontes de recursos para honrar as obrigaçôes financeiras, para trabalhar na reduçáo dos custos e na renegociação de dívidas existentes.

Esses elementos são reforçados pelo fato de $44 \%$ dos entrevistados afirmarem que a reduçáo do número de alunos que vem ocorrendo, com consequente redução da receita, também está entre suas principais preocupaçôes. Esses fatores se somam às preocupaçóes relacionadas à imprevisibilidade do mercado, mencionada por um terço dos entrevistados.

Para os respondentes, a incerteza em relação à situação econômica do País e, principalmente, em relação às políticas que serão aplicadas pelo governo no que diz respeito ao financiamento aos estudantes com recursos públicos mobiliza suas preocupaçóes e gera insegurança nas açóes de planejamento que se tem a realizar para os próximos exercícios.

Para 22\% dos respondentes, o comprometimento financeiro de curto prazo representa uma das principais preocupaçóes na atualidade. Para os gestores em questão, o endividamento de curto prazo e o volume de obrigaçóes assumidas dificulta a gestáo financeira, elevando a sua despesa e gerando mais envolvimento.

Complementarmente, também para $22 \%$ dos entrevistados, a manutenção do perfil da dívida em patamares adequados às condiçōes Institucionais também é uma das principais preocupaçóes, conforme demonstrado na transcriçáo da fala de um dos respondentes, conforme segue: 
[...] nós temos um perfil de dívidas, mesmo que ela seja a longo prazo, ela vai se encurtando. Então a preocupaçáo é manter um perfil de dívidas que mantenha nossos compromissos rigorosamente em dia. $\mathrm{O}$ que até o presente momento está sendo atingido. Com mais captação de recursos do que a gente deseja, sim. Com custo agregado dessa captação, sim. Mas nós não temos os impostos atrasados [...]. (F).

Essa visão também se completa com a manifestação de dois respondentes de que a manutenção do pagamento de salários e tributos em dia reside entre suas preocupações, situação que coincide com o fato das mesmas já terem passado por esse tipo de dificuldade em anos anteriores, o que as leva a colocar esses elementos entre os que mais desejam evitar que ocorram.

Essas preocupaçóes refletem aspectos relacionados à situação econômica atual e à busca de recursos realizada no mercado financeiro em função dos problemas ocorridos a partir de 2015, com a restrição macroeconômica e do acesso ao FIES, com atrasos nos repasses de recursos, e na redução de estudantes que vem ocorrendo a partir de entấo.

Embora o Governo Federal tenha reestabelecido a regularidade do cronograma de repasses de recursos do FIES, mesmo tendo reduzido o acesso a novas vagas, 44\% dos entrevistados relatam que se preocupam com a possibilidade de ocorrem novos atrasos nos repasses de valores. Essa questáo é continuamente monitorada e essa preocupaçáo resulta das sérias dificuldades enfrentadas quando os atrasos já mencionados ocorreram, levando à necessidade de busca de recursos bancários e ao pagamento de juros para fazer frente às obrigaçôes financeiras existentes.

Por fim, as afirmaçôes dos gestores entrevistados que denotaram características ou condiçóes que são consideradas pelos mesmos como decorrências do modelo democrático foram reunidas em uma categoria específica, a ser apresentada a seguir.

Como já foi dito, as Instituiçôes Comunitárias de Ensino Superior apresentam uma série de particularidades em relação às demais e o conhecimento a respeito desses elementos pode fornecer meios de potencialização dos aspectos positivos e de melhoria nos pontos que carecem de desenvolvimento.

A pluralidade é uma das características das Instituições de Ensino Superior, o que não é diferente no âmbito de sua gestão, como já foi visto no início do presente trabalho. No universo pesquisado, o que se observa náo é diferente, entretanto, em se tratando dos profissionais que atuam na área financeira, para $100 \%$ dos casos em análise, a ocupação dos cargos é feita por profissionais com experiência ou formação na área financeira.

A pluralidade também é verificada na composição das reitorias de $89 \%$ das ICES pesquisadas, as quais são compostas por profissionais de diversas áreas do conhecimento. Para a maioria dos gestores entrevistados, essa diversidade é vista como saudável, por proporcionar a visão da gestấo superior sob diversos aspectos, e inerente à condiçấo universitária, conforme defende um dos gestores:

[...] eu não estou imaginando que as pessoas que vêm de outras áreas não consigam ter um certo, eu não vou dizer domínio desses assuntos, mas um conhecimento razoável para discutir e para entender esses assuntos. Eu acho que falta, talvez, a cultura da formaçáo nesta área. Porque eu não posso imaginar também que as pessoas que venham de outras 
áreas que não sejam as áreas mais voltadas à essa questão, que seria a formação em Administração, Contabilidade, talvez Engenharia, eu não posso imaginar que não ocupem cargos importantes na Instituição. Não cabe numa Instituição de ensino como a nossa se propóe, imaginar que nós não vamos ter gestores dessas outras áreas, mais humanas, da educação, da saúde. Então, eu acho que isso é comum, é natural e é necessário que aconteça. (D).

Apenas uma das ICES pesquisadas apresenta certa uniformidade em relação às formaçôes dos ocupantes dos cargos da reitoria, sendo a maioria da área de gestáo ou de ciências exatas. Nesse caso, verifica-se no discurso do entrevistado que tal fator é visto como facilitador para a realização das atividades financeiras, que há mais facilidade de comunicação e de se obter consenso nos encaminhamentos, o que é ilustrado pela afirmaçáo do respondente de que seus pares o entendem, sabem o que ele está falando.

Para 67\% dos entrevistados, há o entendimento de que o caráter de autogestão das ICES pesquisadas deve ser mantido, mas com vistas à otimização das práticas. Complementarmente a essa ideia, $56 \%$ dos respondentes dizem que o caráter comunitário e a autogestão são vistos como aspectos de elevada complexidade. Esses fatores são demonstrados por intermédio da fala do gestor da Universidade C, que pondera os aspectos de decisão quando ocorrida em uma organizaçáo como a em que ele atua:

O fato de ser uma universidade comunitária, te obriga a dividir com os outros do grupo as aflições do momento e a validar as soluções que você está conferindo. Então, apesar de ter autonomia, como eu te disse, você acaba validando com os pares, isso é uma característica de instituição comunitária. O principal fato que seja um complicador é o que todo mundo se considera dono da instituiçãa, desde o público interno até o público externo. Então, você não pode tomar medidas um pouco mais enérgicas em algumas situaçóes [...]. (C).

Para $89 \%$ dos participantes da pesquisa, o aspecto democrático é visto como positivo, mas ele dificulta a aplicação de boas práticas de gestão. Conforme os entrevistados, o universo de alta participação confere as condiçôes para o atingimento da missão das ICES, mas requer competências diferenciadas em relação aos demais tipos de organizaçóes para que se possa dar conta disso. Isso se reforça pela afirmaçáo por parte de $44 \%$ dos respondentes de que o aspecto político é considerado inerente à autogestão, mas que há uma tendência de profissionalização dos agentes envolvidos nesses processos.

Esses elementos demonstram que há um entendimento de que a democracia, a pluralidade e as questóes relacionadas ao modelo de autogestão das ICES são importantes e necessários, porém de alta complexidade e requerem um conjunto de esforços e competências diferenciadas para que se tenha sucesso.

Em suas falas, dois gestores evidenciam essas particularidades inerentes às Comunitárias, um deles enfatizando suas especificidades, seu caráter complexo, e outro apresentando uma visão mais otimista, ressaltando a tendência de aprimoramento identificada com a aplicação da pesquisa:

[...] a questão democrática é pesada, ela permeia todas as relações, né. Num dia o sujeito está como chefe, depois ele está como subordinado, então são situaçốes específicas numa instituição como a nossa que precisam ser consideradas, que não dá para simplesmente 
imaginar que ela seja uma empresa, ela é uma organização e, se ela tivesse dono, provavelmente teriam algumas decisôes que seriam diferentes do que aquelas que são tomadas. $(\mathrm{G})$.

A gente está se construindo, a gente está... a democracia, ou a democracia que se pretende, ela é complexa, tá, não estou dizendo que ela é ruim, eu acho que é boa. Mas ela é complexa. Então, a gente tem que construí-la de forma que consiga ser sustentável. Mas eu acho que a gente não está na fase final dessa construção, a gente está numa fase de construção. (D).

Para um terço dos respondentes, aspectos políticos internos preponderam sobre aspectos técnicos financeiros com muita frequência, entretanto, a perspectiva apresentada por esses gestores é otimista, na medida em que percebem que existe uma tendência de diminuição desses fatores dentro das Universidades onde atuam.

Nesse mesmo sentido, $22 \%$ dos entrevistados manifestaram que muitos encaminhamentos Institucionais, nos diversos níveis hierárquicos, consideram pressupostos acadêmicos e desconsideram pressupostos financeiros. Esses aspectos também são atribuídos à natureza do formato e à cultura Institucional, a qual, na avaliação dos entrevistados, tende a se desenvolver no decorrer do tempo.

Os aspectos verificados nessa categoria coincidem com os observados no estudo de Stiebbe (2014), a qual menciona os aspectos decorrentes da gestão de uma universidade comunitária, destacando que os aspectos democráticos, conforme já mencionado, atribuem morosidade aos processos ao mesmo tempo que possibilitam a participação dos múltiplos atores Institucionais e possibilitam o atingimento de conceitos acadêmicos elevados. Da mesma forma, a pesquisadora evidencia em seu estudo a tendência e necessidade de aprimoramento desse sistema de gestáo.

$\mathrm{Na}$ sequência, apresenta-se a Tabela 1, contendo a síntese das percepçóes sobre as políticas de gestâo institucional, com as subcategorias e as ocorrências com seus respectivos percentuais em reação ao total de ICES participantes do estudo, todas agrupadas em categorias. 
Tabela 1 - Síntese das percepções sobre as políticas de gestão institucional

\begin{tabular}{|c|c|c|}
\hline Categorias & Subcategorias & ICES \\
\hline \multirow{9}{*}{ Dificuldades } & $\begin{array}{l}\text { A Instituição assume perdas financeiras para obter resultados náo financeiros } \\
\text { com muita frequência }\end{array}$ & 5 \\
\hline & $\begin{array}{l}\text { A Instituição tem dificuldade de tomar decisóes que diminuam } \\
\text { significativamente os custos }\end{array}$ & 2 \\
\hline & Associaçáo do conceito de universidade comunitária ao assistencialismo & 1 \\
\hline & Cultura Institucional dificulta as açôes de reduçáo de custos & 2 \\
\hline & Dificuldade por parte dos gestores das demais áreas em tomar decisôes & 2 \\
\hline & $\begin{array}{l}\text { Necessidade de reorganização da pesquisa para gerar conhecimento e receita } \\
\text { como resultados }\end{array}$ & 1 \\
\hline & $\begin{array}{l}\text { O que se ensina em termos de gestão não é aplicado em sua totalidade pela } \\
\text { Instituiçáo }\end{array}$ & 1 \\
\hline & $\begin{array}{l}\text { Os gestores das áreas carecem de conhecimentos financeiros básicos para } \\
\text { qualificar suas decisóes }\end{array}$ & 2 \\
\hline & Superávit é visto como negativo, por ser associado ao lucro dentro da Instituição & 2 \\
\hline \multirow{11}{*}{ Boas práticas } & $\begin{array}{l}\text { A Instituiçáo trabalha para vincular o orçamento ao planejamento com a } \\
\text { utilização da lógica do BSC }\end{array}$ & 1 \\
\hline & $\begin{array}{l}\text { A maioria das proposiçóes da Pró-Reitora Administrativa são aceitas na } \\
\text { Instituiçáo }\end{array}$ & 4 \\
\hline & $\begin{array}{l}\text { As áreas acadêmicas têm um gestor administrativo vinculado à Pró-reitora } \\
\text { Administrativa }\end{array}$ & 1 \\
\hline & $\begin{array}{l}\text { Busca constante de novos serviços resultantes da atividade acadêmica como fonte } \\
\text { de receita }\end{array}$ & 1 \\
\hline & $\begin{array}{l}\text { Elevado grau de controle exercido pela Pró-reitora Administrativa impede gastos } \\
\text { não previstos }\end{array}$ & 4 \\
\hline & $\begin{array}{l}\text { Expansão do stricto sensu viabilizada por programa de bolsas parciais com } \\
\text { recursos Institucionais }\end{array}$ & 1 \\
\hline & $\begin{array}{l}\text { Foco em qualificação de cursos da saúde como forma de fazer frente à } \\
\text { concorrência }\end{array}$ & 2 \\
\hline & $\begin{array}{l}\text { Foi criado um conjunto de critérios que determinam quando um curso deve ser } \\
\text { descontinuado }\end{array}$ & 1 \\
\hline & $\begin{array}{l}\text { Foi criado um programa de formação de gestores com vistas a profissionalizar a } \\
\text { gestão Institucional }\end{array}$ & 1 \\
\hline & Há um setor específico para promover açóes de redução da evasão dos estudantes & 1 \\
\hline & $\begin{array}{l}\text { Intensas negociações são realizadas para contornar as dificuldades da estrutura } \\
\text { colegiada }\end{array}$ & 1 \\
\hline \multirow{7}{*}{$\begin{array}{c}\text { Preocupaçóes } \\
\text { dos gestores }\end{array}$} & Comprometimento financeiro de curto prazo & 2 \\
\hline & Imprevisibilidade do mercado & 3 \\
\hline & Liquidez e manutenção do fluxo de caixa & 8 \\
\hline & $\begin{array}{l}\text { Manutenção do perfil da dívida adequado às condiçóes Institucionais de } \\
\text { pagamento }\end{array}$ & 2 \\
\hline & Manutenção do pagamento de salários e tributos em dia & 2 \\
\hline & Possibilidade de atraso nos repasses de recursos do FIES & 4 \\
\hline & Reduçáo do número de alunos e da receita & 4 \\
\hline
\end{tabular}




\begin{tabular}{|c|c|c|}
\hline Categorias & Subcategorias & ICES \\
\hline \multirow{8}{*}{$\begin{array}{l}\text { Decorrências } \\
\text { do modelo } \\
\text { democrático }\end{array}$} & $\begin{array}{l}\text { Aspectos políticos internos preponderam sobre aspectos técnicos financeiros com } \\
\text { muita frequência }\end{array}$ & 3 \\
\hline & $\begin{array}{l}\text { Diversidade de formaçôes na reitoria, com gestores financeiros da área da gestáo } \\
\text { ou engenharias }\end{array}$ & 8 \\
\hline & $\begin{array}{l}\text { Há o entendimento de que a autogestáo deve ser mantida, com vistas à } \\
\text { otimizaçáo das práticas }\end{array}$ & 6 \\
\hline & $\begin{array}{l}\text { Muitas decisões consideram os pressupostos acadêmicos e desconsideram os } \\
\text { financeiros }\end{array}$ & 2 \\
\hline & $\begin{array}{l}\text { O aspecto democrático é visto como positivo, mas dificulta a aplicaçáo de boas } \\
\text { práticas de gestão }\end{array}$ & 8 \\
\hline & $\begin{array}{l}\text { O aspecto político é considerado inerente à autogestáo e a tendência é de } \\
\text { profissionalizaçáo }\end{array}$ & 4 \\
\hline & $\begin{array}{l}\text { O caráter comunitário e a autogestão são vistos como aspectos de elevada } \\
\text { complexidade }\end{array}$ & 5 \\
\hline & Os cargos financeiros costumam ser ocupados por profissionais da área financeira & 9 \\
\hline
\end{tabular}

Fonte: Autores (2020)

Os dados obtidos elucidam uma necessidade de melhoria nas políticas de gestão de várias das ICES pesquisadas, principalmente no que diz respeito à capacitação dos demais gestores Institucionais para que os mesmos tenham melhores condiçóes de tomar decisóes com impacto financeiro e passem a ter um perfil mais voltado à gestão, sem prejuízo de suas competências acadêmicas.

\section{CONSIDERAÇÓES FINAIS}

A aplicação da pesquisa possibilitou a visualização de um conjunto de Instituiçóes caracterizada pela alta complexidade de gestáo, o que se constitui em um grande desafio para seus dirigentes. Aspectos como a democracia, a multiplicidade de áreas do conhecimento e os elementos decorrentes dessas particularidades, sobretudo o aspecto político, contribuem para o estabelecimento de uma estrutura altamente desafiante para seus gestores, conforme ficou evidenciado nos resultados apresentados.

As políticas de gestão institucional do grupo avaliado permitem, em alguns casos, a preponderância de aspectos políticos em detrimento de aspectos técnicos financeiros nas tomadas de decisóes, assumindo as ICES, muitas vezes, perdas financeiras para a obtenção de resultados não financeiros. Entretanto, os entrevistados demonstram que essa é uma característica inerente ao caráter comunitário, democrático e de priorização da qualidade acadêmica, o que se confirma pelos bons resultados nas avaliaçóes do Ministério da Educação apresentados pelas ICES em questáo.

Apesar disso, ficou destacado que existe a consciência da necessidade de aprimoramento das práticas de gestão, tendo em vista que, de acordo com os respondentes, as particularidades mencionadas dificultam a aplicação de técnicas de gestão. Cabe destacar que essas condiçóes coincidem com os resultados de outras pesquisas, que apresentam o ambiente universitário como de difícil aplicação das boas práticas de gestão ensinadas pelas IES em sala de aula. 
Acerca das competências essenciais e recursos estratégicos de uma Instituição Comunitária de Ensino Superior, Stiebbe (2014) descreve uma ICES como uma organização de alta complexidade, permeada por elementos como a democracia, a alta participação dos diversos componentes da comunidade acadêmica e o foco na excelência acadêmica. Entre os desafios da gestão universitária elencados pela autora, destacam-se as limitaçóes decorrentes do modelo democrático, as quais restringem a autonomia dos gestores e trazem morosidade ao processo decisório.

As Instituiçóes Comunitárias de Ensino Superior representam um tipo de organização cujos reflexos causados pela sua atuação nas comunidades nas quais estão inseridas resultam em desenvolvimento humano, científico e tecnológico. Os resultados decorrentes do aprimoramento das suas práticas de gestão, portanto, podem representar importantes contribuiçóes a estas comunidades e a todos os atores envolvidos. Portanto, o presente estudo buscou contribuir com esse processo, fornecendo subsídios para o entendimento acerca das políticas de gestão utilizadas pelo conjunto pesquisado, podendo auxiliar no desenvolvimento de organizaçóes congêneres pelo aperfeiçoamento de suas práticas de gestão.

\section{REFERÊNCIAS}

ASSOCIAÇÃO BRASILEIRA DAS UNIVERSIDADES COMUNITÁRIAS. Associação brasileira das universidades comunitárias. Apresenta informaçóes gerais sobre a associação. Disponível em: <http://www.abruc.org.br/>. Acesso em: 20 out. 2020.

BALZER, W. K.; BRODKE, M. H.; KIZHAKETHALACKAL, E. T. Lean higher education: successes, challenges, and realizing potential. International Journal of Quality \& Reliability Management, v. 32, n. 9, p. 924-933, 2015.

BARDIN, L. Análise de Conteúdo. Lisboa, Portugal: Ediçôes 70, 288p., 2015.

BELL, L. Management skills in primary schools. Routledge, 2018.

BRASIL. Lei 12.881, de 12 de novembro de 2013. Dispóe sobre a definição, qualificação, prerrogativas e finalidades das instituições comunitárias de educação superior - ICES, disciplina o termo de parceria e dá outras providências. Disponível em: <http:// www.planalto.gov.br/ccivil_03/_Ato2011-2014/2013/Lei/L12881.htm>. Acesso em: 2 out. 2020.

. Lei $\mathrm{N}^{\circ}$ 13.005, de 25 de junho de 2014. Aprova o Plano Nacional de Educação - PNE e dá outras providências. Disponível em: <http://www.planalto.gov.br/ CCIVIL_03/_Ato2011-2014/2014/Lei/L13005.htm>. Acesso em: 30 set. 2020.

CAMPOS, P.; LIMA, C.; LIMA, M.; LIMA, M. O Balanced Scorecard como sistema de avaliação de desempenho desdobrado nas áreas de gestão, ensino, pesquisa e extensão 
em uma instituição de ensino superior comunitária. Revista Gestão Universitária na América Latina-GUAL, v. 10, n. 1, p. 39-61, 2017.

CONSELHO NACIONAL DE EDUCAÇÃO. Plano Nacional de Educação (PNE) 2011-2020. Políticas e Gestão da Educação Superior no Brasil. Disponível em: <http:// portal.mec.gov.br/index.php?option=com_docman\&view=download \&alias=11947documento-referencia-pdf\&Itemid=30192>. Acesso em: $18 \mathrm{dez} .2020$.

CONSÓRCIO DAS UNIVERSIDADES COMUNITÁRIAS GAÚCHAS. COMUNG mobiliza sociedade para a aprovaçáo de Projeto de Lei que destina recursos ao FIES. Apresenta notícia sobre o COMUNG Disponível em: <http://www.comung.org.br/ artigos/exibir/comung-mobiliza-sociedade-para-a-aprovacao-de-projeto-de-lei>. Acesso em: 20 set. 2020 .

Sobre o COMUNG. Apresenta informações gerais sobre o COMUNG.

Disponível em: <http://www.comung.org.br/sobre/exibir/comung>. Acesso em: 14 fev. 2020.

DÍEZ, F.; VILLA, A.; LOPEZ, A.L.; IRAURGI, I. Impacto dos sistemas de gestão da qualidade no desempenho de centros educacionais: políticas educacionais e processos de gestão. Heliyon, v. 6, n. 4, pág. e03824, 2020.

DITTADI, J. R.; SOUZA, Marcos Antonio de. Práticas de gestão adotadas em instituiçóes de ensino superior estabelecidas no estado de Santa Catarina. Espacios (Caracas), v. 30, p. 17-20, 2009.

GÓIS, E. S.; SALERNO, S. K. A EDUCAÇÃO SUPERIOR NO BRASIL: AJUSTE JUSTO. Seminário Nacional e Seminário Internacional Políticas Públicas, Gestão e Práxis Educacional, v. 8, n. 8, 2021.

HAIR, J. F. et al. Fundamentos de métodos de pesquisa em administração. Porto Alegre: Bookman, 2005.

HANSMANN, H. B. The role of nonprofit enterprise. The Yale Law Journal, v. 89, n. 5, p. 835-902, 1980.

HOFMANN, M. A.; MCSWAIN, D. Financial disclosure management in the nonprofit sector: A framework for past and future research. Journal of accounting literature, v. 32, n. 1, p. $61-87,2013$.

HOQUE, K. E.; ALAM, G. M.; GHANI, M. F. A. Principals' Roles under School Based Management that Influence School Improvement. Social Pedagogy, p. 311, 2011.

INSTITUTO NACIONAL DE ESTUDOS E PESQUISAS EDUCACIONAIS ANÍSIO TEIXEIRA. Censo da educação superior 2016 - Notas estatísticas. Apresenta 
informações sobre o Censo da Educação Superior de 2019. Disponível em: <http:// download.inep.gov.br/educacao_superior/censo_superior/documentos/2016/notas_ sobre_o_censo_da_educacao_superior_2019.pdf >. Acesso em: $14 \mathrm{dez} .2020$.

. Indicadores de Qualidade - INEP Conceitos e pontuaçáo. Apresenta

informaçôes sobre os indicadores de qualidade do INEP. Disponível em: <http://portal. inep.gov.br/web/guest/indicadores-de-qualidade>. Acesso em: 14 dez. 2020.

JEFFERSON, M.; ANDERSON, M. Transforming schools: Creativity, critical reflection, communication, collaboration. Bloomsbury Publishing, 2017.

MACHADO, V. de C.; BARASSUOL, R. M. Viabilidade econômico-financeira da migraçáo do mercado cativo para o mercado livre de energia: Um estudo de caso da universidade de Cruz Alta. X Seminário Internacional sobre Desenvolvimento Regional, 2019.

ROTH, L. et al. A estrutura do ensino superior no Brasil. Revista Gestáo Universitária na América Latina - GUAL, v. 6, n. 3, p. 111-126, 2013.

SARQUIS, A. B.; HOECKESFELD, L.; SOARES, J. C.; DIAS, A. B. S. M. S.; LIMA, M. A. Posicionamento de marca: estudo de caso em Instituições Comunitárias de Ensino Superior. Revista Brasileira de Gestáo e Inovaçáo, v. 5, n. 1, p. 125-154, 2017.

STEIN, L. Schools Need Leaders-Not Managers: It's Time for a Paradigm Shift. Journal of Leadership Education, v. 15, n. 2, 2016.

STIEBBE, V. A. L. Recursos estratégicos e competências essenciais em uma instituição de ensino superior. Dissertação (Programa de Pós-Graduação em Administração - Mestrado Profissional) - Universidade de Santa Cruz do Sul, Santa Cruz do Sul, 2014.

STOLL, L. Capacity building for school improvement or creating capacity for learning? A changing landscape. Journal of educational change, v. 10, n. 2, p. 115-127, 2009.

THIEMANN, I. R. M.; SILVA, M. M.; SEIBERT, R. M.; SILVA, R. C. F.

Responsabilidade social: indicadores para a evidenciação de Instituiçóes Comunitárias de Ensino Superior a partir da perspectiva dos discentes. Revista GESTO, v. 6, n. 2, p. 96$112,2018$.

THOONEN, E. E.; SLEEGERS, P. J.; OORT, F. J.; PEETSMA, T. T. Building schoolwide capacity for improvement: The role of leadership, school organizational conditions, and teacher factors. School effectiveness and school improvement, v. 23, n. 4, p. 441460, 2012. 
WENDLAND, C. N.; SCHWANTZ, P. I.; LIMA, J. I.; BORTOLASO, I. V.; LARA, D. M. Qualidade de vida no trabalho: uma análise da percepção de colaboradores da geração y. Brazilian Journal of Development, v. 7, n. 9, p. 86674-86690, 2021.

YIN, R. K. Estudo de caso: planejamento e métodos. 5. ed. Porto Alegre: Bookman, 2015.

ZAINON, S.; ATAN, R.; WAH, Y. B. An empirical study on the determinants of information disclosure of Malaysian non-profit organizations. Asian Review of Accounting, v. 22, n. 1, p. 35-55, 2014.

ZANIN, A.; POLI, O.; MOURA, G.; JUNG, C.; CATEN, C. Definição de painel de indicadores de desempenho para instituiçôes comunitárias de ensino superior. Revista Gestáo Universitária na América Latina-GUAL, v. 8, n. 2, p. 01-27, 2015. 